\title{
Metronomic capecitabine with aromatase inhibitors for patients with metastatic hormone-receptor positive, HER2-negative breast cancer
}

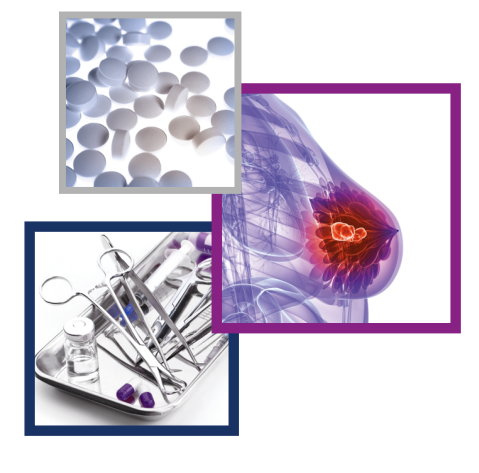

\author{
Bader A Abdelmaksoud*,1 (iD), Mostafa M Toam ${ }^{1}$ \& Alaa A Fayed ${ }^{1}$ \\ ${ }^{1}$ Department of Clinical Oncology \& Nuclear Medicine, Faculty of Medicine, Zagazig University, Elgamaa st 44519, Zagazig, Egypt \\ *Author for correspondence: bader6a@yahoo.com
}

\begin{abstract}
Aim: To evaluate the efficacy and safety of combined metronomic capecitabine with aromatase inhibitors (Als) for patients with newly diagnosed metastatic hormone-receptor positive, HER2-negative breast cancer. Patients \& methods: A total of 41 women with a diagnosis of metastatic hormone-receptor positive, HER2-negative breast cancer received oral metronomic capecitabine, $500 \mathrm{mg} / \mathrm{m}^{2}$ twice daily combined with an Al. Results: After a median follow-up of 24 months (9-50), a median of 15 months of treatment were completed, the median time to progression was 15 months (12.6-17.3) and the median overall survival was 37 months (23.6-50.4). The treatment was tolerated with less than $10 \%$ grade 3 toxicities. Conclusion: Combination of metronomic capecitabine and Als appears to be safe and has encouraging results in advanced hormone-receptor positive, HER2-negative breast cancer.
\end{abstract}

First draft submitted: 24 April 2019; Accepted for publication: 6 June 2019; Published online: 3 October 2019

Keywords: advanced breast cancer $\bullet$ Als $\bullet$ capecitabine $\bullet$ chemo-endocrine therapy $\bullet$ metronomic chemotherapy $\bullet$ side effects

Breast cancer is the second most common cancer overall, the most common cancer in women and the leading cause of cancer death, accounting for (11.6\%) of all newly diagnosed cancer worldwide [1]. Although there are marked advances in methods of screening and treatment modalities for patients with breast cancer, the treatment of advanced or metastatic breast cancer (MBC) still has many challenges with modest response rates regarding the improvement of overall survival (OS) and a median survival of 18-24 months [2]. Generally, MBC is considered to be a treatable but not a curable disease and so the aim of the treatment of such cases is for the optimization of both length and quality of life [3]. Cases with positive hormonal receptors, either estrogen receptor (ER) or progesterone receptor (PR), represent $\geq 70 \%$ of all newly diagnosed breast cancer patients [4]. Hormone therapy is the cornerstone for treatment of minimally symptomatic cases according to menopausal status, in premenopausal patients, tamoxifen is the treatment drug of choice, while in postmenopausal patients, aromatase inhibitors (AIs) are more suitable and demonstrate significant survival benefits [5]. Treatment of hormone-receptor positive MBC patients with chemotherapy is usually reserved for patients with life-threatening conditions. For patients treated with hormonal therapy who have a good overall response rate (ORR; endocrine-responsive), treatment failure and disease progression is expected to occur at any time and subsequently, second- or even third-line hormonal therapy is tried. Theoretically, the treatment of cancer with two or more anticancer agents, each having different mechanisms of action, will more likely achieve the anticancer effect than use of a single agent alone; this was evidenced when a human breast cancer xenograft was treated with the combination of capecitabine and letrozole [6].

Administration of an anticancer agent at frequent low doses without long drug-free periods is known as metronomic chemotherapy [7]. Scientifically, conventional chemotherapy targets the proliferation of vascular endothelium but during the off-treatment periods, the antiangiogenic effects stop due to the recovery of the endothelial cell. This might be overcome by continuing of low doses [8]. 
Recent preclinical and clinical studies have shown that the chemo-endocrine combination of AIs or fulvestrant with chemotherapy can be well tolerated and has synergistic effects that enhanced the tumor growth suppression [914]. The combination of metronomic capecitabine and AIs has been evaluated in various studies, in which the results were promising and encouraged further research $[23,24,27]$. In addition, other studies have demonstrated a better ORR if metronomic chemotherapy is combined with AIs [28]. Based on the results of previous research, we conducted this study to evaluate the efficacy and toxicity of combined metronomic capecitabine with AIs for patients with newly diagnosed metastatic hormone-receptor positive, HER2-negative breast cancer.

\section{Patients \& methods}

Eligibility criteria

This study was conducted in the Clinical Oncology and Nuclear Medicine Department of Zagazig University Hospital from March 2015 to July 2018, in which 41 women with a confirmed diagnosis of metastatic hormone receptor-positive, HER2-negative breast cancer were enrolled. Patients fulfilled the following inclusion criteria: age $\geq 18$ years, eastern cooperative oncology group (ECOG) performance status $0-2$, adequate organ and bone marrow functions especially (serum creatinine $\leq 2 \mathrm{mg} / \mathrm{dl}$, transaminases $\leq 3 \mathrm{ULN}$, serum bilirubin $\leq 2 \mathrm{mg} / \mathrm{dl}$, ANC count $\geq 1.5 \times 10^{9} / \mathrm{l}$, platelets count $\geq 100 \times 10^{9} / \mathrm{l}$ and hemoglobin $\geq 10 \mathrm{~g} / \mathrm{dl}$ ) and no prior systemic anticancer therapy. The main exclusion criteria were; patients with symptomatic visceral metastasis that were at high risk to develop life-threatening conditions in the short term, symptomatic-uncontrolled CNS metastases and other concurrent cancer elsewhere in the body. Also, patients with concurrent serious, uncontrolled medical illness as uncontrolled infection and intercurrent psychiatric illness were ineligible. Written informed consent was taken from every patient.

\section{Study design \& treatment plan}

This is a single institution, Phase II single-arm study. Patients who met the above inclusion criteria received oral metronomic capecitabine $500 \mathrm{mg} / \mathrm{m}^{2}$, per-oral bid D1-D21 combined with once daily dose of AI either Letrozole $2.5 \mathrm{mg}$ or Anastrozole $1 \mathrm{mg}$ or Exemestane $25 \mathrm{mg}$ D1-D21. Treatment continued without interruption for stable and responsive cases until disease progression, intolerable toxicities or patient refusal to continue treatment. For pre/perimenopausal women, luteinizing hormone-releasing hormone agonist was ordered at least 28 days before commencing treatment then continued monthly during treatment. Also, palliative radiotherapy was given if highly indicated as in cases with (cervical vertebra, neck femur or painful metastasis) or bone-targeted therapy (denosumab) for other bone metastasis.

\section{Response assessment \& patients follow-up}

Before and during treatment, patients were monitored by; full medical history, general and local physical examination, chest x-ray, abdomen-pelvic ultrasound or CT scans and isotopic bone scan. Laboratory studies included complete blood count, renal function, liver function tests and tumor markers. The first evaluation was done after three cycles ( 2 months) and every 3 months then after. Response assessment was based on revised RECIST guideline [15]. Grading of toxicity was based on the NCI common terminology criteria for adverse events.

\section{End points}

The primary end points of this study were time to progression (TTP) and ORR. Secondary end points were the toxicity and OS.

\section{Statistical analysis}

All statistics were performed using SPSS 22.0 for Windows (SPSS Inc., IL, USA) and MedCalc windows (MedCalc Software bvba 13, Ostend, Belgium). The TTP was defined as the time from the beginning of treatment to the date of progression or the most recent contact that patient was known as progression free. The OS was defined as the time from the beginning of treatment to death or the most recent follow-up (censored). Distributions of this time-to-event were estimated by Kaplan-Meier analysis and plot. All tests were two-sided and a p-value $<0.05$ was considered significant.

\section{Results}

Patient characteristics

The clinicodemographic characteristics of study patients were shown in Table 1. The median age of the patients 
Table 1. Clinicopathological parameters and treatment outcome of the study patients.

\begin{tabular}{|c|c|c|c|c|c|}
\hline Parameters & \multicolumn{2}{|c|}{$\begin{array}{l}\text { All patients } \\
\qquad(\mathrm{N}=41)\end{array}$} & Parameters & \multicolumn{2}{|c|}{$\begin{array}{l}\text { All patients } \\
\qquad(\mathrm{N}=41)\end{array}$} \\
\hline Age (years): & & & Bone metastasis: & & \\
\hline - Median (range) & 54 & $(28-69)$ & - Present & 27 & $65.9 \%$ \\
\hline$-\leq 55$ years & 22 & $53.7 \%$ & Liver metastasis: & & \\
\hline Menopausal status: & & & Lung metastasis: & & \\
\hline - Premenopausal & 10 & $24.4 \%$ & - Absent & 24 & $58.5 \%$ \\
\hline - Perimenopausal & 5 & $12.2 \%$ & - Present & 17 & $41.5 \%$ \\
\hline - Postmenopausal & 26 & $63.4 \%$ & Number of cycles: & & \\
\hline ECOG PS: & & & - Mean \pm SD & 21.15 & \pm 13.14 \\
\hline ER: & & & - Partial response & 9 & $22 \%$ \\
\hline -Negative & 10 & $24.4 \%$ & - Stable disease & 24 & $58.5 \%$ \\
\hline -Positive & 31 & $75.6 \%$ & - Progressive disease & 4 & $9.8 \%$ \\
\hline PR: & & & $\begin{array}{l}\text { Follow-up duration } \\
\text { (months): }\end{array}$ & & \\
\hline - Negative & 13 & $31.7 \%$ & - Mean \pm SD & 24.58 & \pm 12.13 \\
\hline - Positive & 28 & $68.3 \%$ & - Median (range) & 24 & $(9-50)$ \\
\hline ER/PR: & & & Progression: & $(N=37)$ & \\
\hline$-E R+/ P R-$ & 14 & $31.7 \%$ & - No progression & 0 & $0 \%$ \\
\hline - ER-/PR+ & 10 & $24.4 \%$ & - Within 15 months & 20 & $54.1 \%$ \\
\hline
\end{tabular}

Categorical variables were expressed as number (percentage); continuous variables were expressed as mean \pm standard deviation \& median (range).

ER: Estrogen receptor; PR: Progesterone receptor; ECOG PS: Eastern Cooperative Oncology Group Performance Status; SD: Standard deviation.

was 54 (range, $28-69)$ where 21 patients $(53.7 \%)$ were $\leq 55$ years. Ten patients $(24.4 \%)$ were premenopausal, five (12.2\%) were perimenopausal and the remaining (63.4\%) were postmenopausal, the majority of cases had ECOG PS 1. Regarding the hormonal receptors status, $43.9 \%$ of patients were ER+, PR+, 31.7\% of patients were ER+, PR- and $24.4 \%$ were ER-, PR+. Around $56.1 \%$ of patients had single organ metastasis at presentation while the remaining $43.9 \%$ had multiorgan metastasis. Bone, liver and lung metastasis presented in 65.9, 41.5 and 41.5\% of patients, respectively.

\section{Treatment outcome}

After a median follow-up of 24 months (range: 9-50), 21 patients (51.2\%) were still alive at the end of this study. For all patients, a median of 20 cycles (range: 2-50) of therapy were given, for which 4 (9.8\%) cases achieved complete response, 9 (22\%) partial response, 24 (58.5\%) stable disease and 4 cases (9.8\%) had progressive disease after initial assessment. The ORR was 31.8\%. During that period, the TTP was 15 months (range: 12.61-17.38) where 20 patients progressed within 15 months of treatment, 17 patients progressed after 15 months and 4 were excluded due to progression after the initial assessment and shifted to another line of treatment. The median time of OS was 37 months (range: 23.56-50.43; Table 1, Figure 1). The effect of the clinicopathological parameters of studied patients on both TTP and OS was analyzed in Table 2 and 3 and the results showed that there was no significant effect of these parameters on TTP except single versus multiorgan metastasis (p-value: 0.021 ) and number of cycles ( $\mathrm{p}$-value: 0.01 ); also, it was noted that most of the patient or tumor characteristics had no 

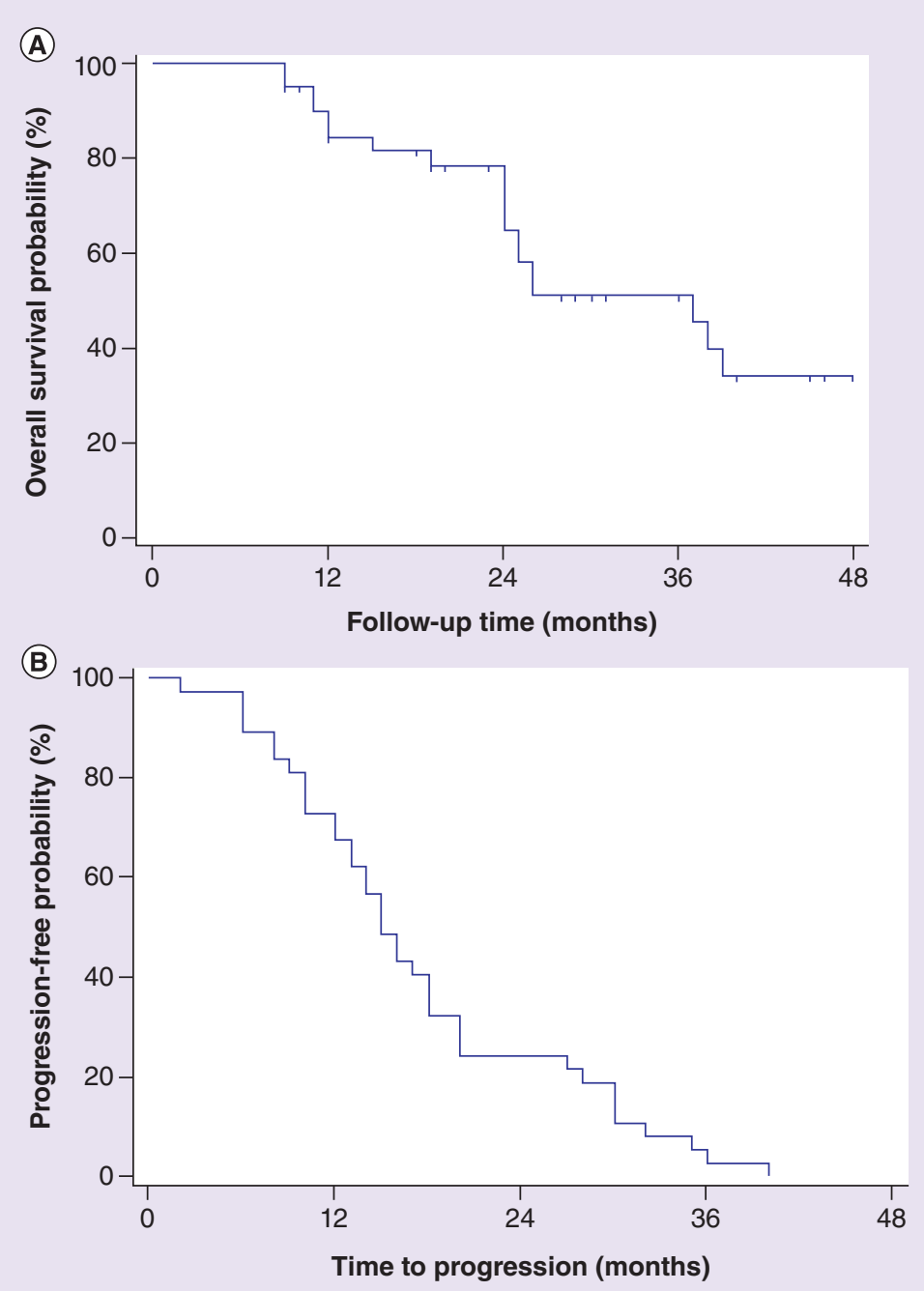

Figure 1. Kaplan-Meier plots of the studied breast cancer patients $(\mathbf{N}=\mathbf{4 1})$. (A) For overall survival, $(B)$ for time to progression.

significant impact on OS except age (p-value: 0.017) and initial response (p-value: 0.024). Regarding hormone receptor status, we sub stratified patients into three groups, group $1(\mathrm{ER}+, \mathrm{PR}+)$, group $2(\mathrm{ER}-, \mathrm{PR}+)$ and group 3 (ER+, PR-), and our results showed that patients in group 3 had prolonged both median TTP and OS than groups 1 or 2 (Figure 2). Regarding treatment-related effects, a summary of treatment-related toxicities is shown in Table 4. In general, the treatment was well tolerated and most patients had no treatment interruption due to treatment-related toxicities, however, five patients $(19.5 \%)$ had a dose reduction of capecitbine due to grade 3 hand-foot syndrome. The most frequently seen other toxicities were generalized fatigue, in which most of it was grade 2-3. Grade 4 treatment-related toxicities were observed in only four patients; two (4.8\%) developed grade 4 hypokalemia and managed actively without any dose reduction or interruption, one (2.4\%) experienced grade 4 diarrhea that required hospitalization and temporary capecitabine dose interruption for one week but after resolving, the initial dose was resumed, also, there was one patient (2.4\%) who developed grade 4 vomiting. Other treatment-related side effects were mild and had no effect on the treatment.

\section{Discussion}

The first-line treatment of metastatic hormone-receptor positive, HER2-negative breast cancer is usually endocrine therapy alone. Tamoxifen, AIs and fulvestrant are the most famous agents used in this setting with PFS of 6, 9-13 and 17-23 months, respectively [16-19]. Based on the results of several trials, AIs showed superiority compared 
Table 2. Relationship between clinicopathological parameters and progression among the study patients $(\mathrm{N}=37)$.

Clinicopathological parameters

\begin{tabular}{|c|c|c|c|c|c|}
\hline \multicolumn{6}{|c|}{ Progression } \\
\hline & $\begin{array}{l}\text { II patients } \\
(\mathrm{N}=37)\end{array}$ & & $\begin{array}{l}15 \text { months } \\
=20)\end{array}$ & & $\begin{array}{l}15 \text { months } \\
J=17)\end{array}$ \\
\hline Number & Percentage & Number & Percentage & Number & Percentage \\
\hline
\end{tabular}

Age (years):

- Mean \pm SD

52.53

$\pm 10.75$

53.25

$\pm 10.93$

52.53

- Median (range)

54

$-\leq 55$ years

- >55 years

20

(28-69)

56

\pm 10.93
$(28-68)$

52.53
50
9

17

$54.1 \%$

56
11

$55 \%$

$9 \quad 52.9 \%$

9
8

Menopausal status:

\section{- Premenopausal}

- Perimenopausal

- Postmenopausal

$17 \quad 45.9 \%$

9

8

P.

p-value

$\begin{array}{ll}9 & 24 \\ 4 & 10.8 \\ 24 & 64.9\end{array}$

\begin{tabular}{l}
$24.3 \%$ \\
$10.8 \%$ \\
$64.9 \%$ \\
\hline
\end{tabular}

ECOG PS:

- ECOG 0
- ECOG 1
- ECOG 2

ER:

\begin{tabular}{l} 
- Negative \\
- Positive \\
\hline PR:
\end{tabular}

13

$\begin{array}{ll}20 & 54.1 \% \\ 4 & 10.8 \%\end{array}$

4
2
14

\begin{tabular}{l}
\hline $44.4 \%$ \\
$50 \%$ \\
\hline $58.3 \%$ \\
\hline
\end{tabular}

$\begin{array}{ll}7 & 18.9 \% \\ 30 & 81.1 \%\end{array}$

6

\begin{tabular}{l}
$46.2 \%$ \\
$55 \%$ \\
$75 \%$ \\
\hline
\end{tabular}

5
2

\begin{tabular}{l} 
\pm 10.85 \\
$(38-69)$ \\
$45 \%$ \\
$47.1 \%$ \\
\hline
\end{tabular}

0.879

$-N$

\begin{tabular}{lll} 
- Negative & 13 & 35 \\
\hline - Positive & 24 & $64.9 \%$ \\
\hline Metastasis: & & \\
\hline
\end{tabular}

\begin{tabular}{|c|c|c|c|c|c|c|c|}
\hline - Single organ & 23 & $62.2 \%$ & 9 & $39.1 \%$ & 14 & $60.9 \%$ & $0.020^{\ddagger}$ \\
\hline - Multiple organs & 14 & $37.8 \%$ & 11 & $78.6 \%$ & 3 & $21.4 \%$ & \\
\hline \multicolumn{8}{|l|}{ Bone metastasis: } \\
\hline - Absent & 12 & $32.4 \%$ & 8 & $66.7 \%$ & 4 & $33.3 \%$ & $0.286^{\ddagger}$ \\
\hline - Present & 25 & $67.6 \%$ & 12 & $48 \%$ & 13 & $52 \%$ & \\
\hline \multicolumn{8}{|l|}{ Liver metastasis: } \\
\hline - Absent & 23 & $62.2 \%$ & 10 & $43.5 \%$ & 13 & $56.6 \%$ & $0.098^{\ddagger}$ \\
\hline - Present & 14 & $37.8 \%$ & 10 & $71.4 \%$ & 4 & $28.6 \%$ & \\
\hline \multicolumn{8}{|l|}{ Lung metastasis: } \\
\hline - Absent & 23 & $62.2 \%$ & 10 & $43.5 \%$ & 13 & $56.6 \%$ & $0.098^{\ddagger}$ \\
\hline - Present & 14 & $37.8 \%$ & 10 & $71.4 \%$ & 4 & $28.6 \%$ & \\
\hline \multicolumn{8}{|l|}{ Number of cycles: } \\
\hline- Mean \pm SD & 23.16 & \pm 12.20 & 15.10 & \pm 6.04 & 32.65 & \pm 10.72 & $<0.001^{\dagger}$ \\
\hline - Median (range) & 21 & $(3-52)$ & 15 & $(3-30)$ & 27 & $(20-52)$ & \\
\hline \multicolumn{8}{|l|}{ Response: } \\
\hline - Complete response & 4 & $10.8 \%$ & 1 & $25 \%$ & 3 & $75 \%$ & $0.304^{\ddagger}$ \\
\hline - Partial response & 9 & $24.3 \%$ & 4 & $44.4 \%$ & 5 & $55.6 \%$ & \\
\hline - Stable disease & 24 & $64.9 \%$ & 15 & $62.5 \%$ & 9 & $37.5 \%$ & \\
\hline
\end{tabular}

Categorical variables were expressed as number, continuous variables were expressed as mean \pm standard deviation and median (range).

$\dagger$ Mann-Whitney U test.

$\ddagger$ Chi-square.

$p<0.05$ is significant.

with tamoxifen for postmenopausal patients with advanced breast cancer regarding overall response, TTP, and OS (20-22). The progression of the disease is expected following endocrine therapy and this is usually due to the development of intrinsic or extrinsic endocrine resistance [22,23]. Although the endocrine resistance is the principal cause of treatment failure and disease progression, there is another reason that may contribute to disease progression; the proliferation and growth of other hormonal negative cells in the tumor. As it is known, not all tumor cells are 
Table 3. Relationship between clinicopathological parameters and mortality among the study patients $(\mathrm{N}=41)$. Clinicopathological parameters

\begin{tabular}{|c|c|c|c|c|c|}
\hline \multicolumn{6}{|c|}{ Mortality } \\
\hline & $\begin{array}{l}\text { atients } \\
=41 \text { ) }\end{array}$ & & $\begin{array}{l}\text { Alive } \\
=21 \text { ) }\end{array}$ & & $\begin{array}{l}\text { Died } \\
I=20)\end{array}$ \\
\hline Number & Percentage & Number & Percentage & Number & Percentage \\
\hline
\end{tabular}

Age (years):

- Mean \pm SD

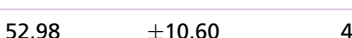

- Median (range)

52.98

- $\leq 55$ years

$\pm 10.60$

49

(28-69)

49
47

$\pm 10.10$

$53.7 \%$

(28-65)

57.15

$\pm 9.67$

59.50

(37-69)

$19 \quad 46.3 \%$

$68.2 \%$

7

$31.8 \%$

p-value

$->55$ years

19

$46.3 \% \quad 6$

$31.6 \%$

13

$68.4 \%$

Menopausal status:

- Premenopausa

- Perimenopausal

- Postmenopausal

10

$24.4 \%$

\begin{tabular}{ll}
10 & $24.4 \%$ \\
5 & $12.2 \%$ \\
\hline
\end{tabular}

7

\begin{tabular}{l}
$70 \%$ \\
\hline $80 \%$ \\
\hline $38.5 \%$ \\
\hline
\end{tabular}

3

$30 \%$

$30 \%$

$20 \%$

ECOG PS:

$63.4 \%$

4
10

$38.5 \%$

1
16

$61.6 \%$

- ECOG 0

$\begin{array}{ll}14 & 34.1 \% \\ 22 & 53.7 \%\end{array}$

9
10
2

$64.3 \%$

$12.2 \%$

$64.3 \%$
$45.5 \%$
$40 \%$

5
12
3

$35.7 \%$
$54.5 \%$
$60 \%$

- ECOG 1

5

ER:

\section{- Negative}

- Positive

PR:

- Negative

- Positive

Metastasis:

- Single organ

- Multiple organs

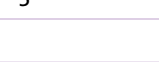

Bone metastasis:

- Absent

- Present

$10 \quad 24.4 \%$

$31 \quad 75.6 \%$

6

$40 \%$

$0.017+$ 

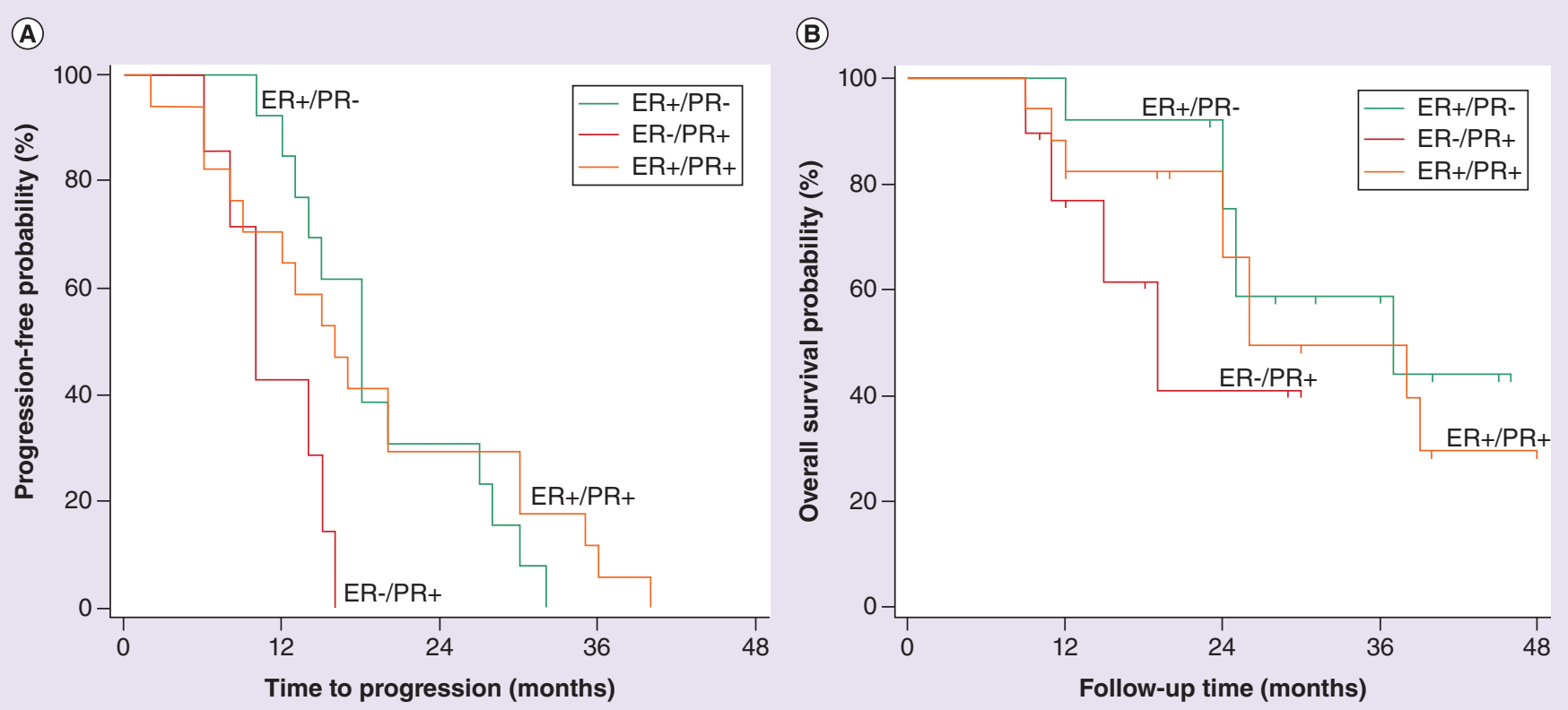

Figure 2. Kaplan-Meier plots of the studied breast cancer patients stratified by estrogen receptor and progeterone receptor status ( $\mathrm{N}=\mathbf{4 1 )}$. (A) For time to progression, (B) for overall survival.

Table 4. Treatment-related adverse effects.

\begin{tabular}{llll}
\hline AEs & \multicolumn{2}{c}{ Grades } & Grade 4, N (\%) \\
\cline { 2 - 4 } 1. Hand-foot syndrome & All grades, N (\%) & Grade 3, N (\%) & 0 \\
2. Nausea & $16(39 \%)$ & $5(12.5 \%)$ & 0 \\
3. Diarrhea & $12(29 \%)$ & 0 & $1(2.4 \%)$ \\
4. Vomiting & $10(24.4 \%)$ & $2(4.8 \%)$ & 0 \\
5. Fatigue & $10(24.4)$ & $2(4.8 \%)$ & 0 \\
6. Headache & $15(41.5 \%)$ & $3(7.3 \%)$ & 0 \\
7. Peripheral edema & $10(24.4 \%)$ & $2(4.8 \%)$ & 0 \\
8. Arthralgia & $10(24.4 \%)$ & 0 & 0 \\
9. Back pain & $8(19.5 \%)$ & 0 & 0 \\
10. Anxiety & $8(19.5 \%)$ & 0 & 0 \\
11. Constipation & $3(7.3 \%)$ & 0 & $2(4.8)$ \\
12. Hypokalemia & $7(17.5 \%)$ & 0 & 0 \\
13. Skin pigmentation & $6(14.6 \%)$ & $2(4.8 \%)$ & 0 \\
14. Skin rash & $7(17.5 \%)$ & $2(4.8 \%)$ & 0 \\
15. Dizziness & $8(19.5 \%)$ & $2(4.8 \%)$ & 0 \\
16. Peripheral neuropathy & $6(14.6 \%)$ & 0 & 0 \\
17. Dyspnea & $5(12.2 \%)$ & 0 & 0 \\
18. Cough & $10(24.4 \%)$ & 0 & 0 \\
19. Pyrexia & $5(12.5 \%)$ & 0 & \\
20. Urinary tract infection & $4(9.6 \%)$ & & \\
\hline AE: Adverse effect. & & & 0 \\
\hline
\end{tabular}

hormone-receptor positive, some remain receptor negative, therefore, endocrine treatment alone is not sufficient to kill or prevent the growth of those cells [24]. Combination of tamoxifen with chemotherapy in the treatment of breast cancer was not recommended in all guidelines, however, combinations of either fulvestrant or AIs with chemotherapy showed significant improvement in both PFS and ORRs $[12,21,25]$. The oral form of fluoropyrimidine (capecitabine), which acts as a pro-drug of 5-fluorouracil, is often preferred by the patients above the continuous infusion form [26]. In the current study, efficacy and toxicity of AIs combined with oral metronomic capecitabine were investigated as a first-line treatment in patients with newly diagnosed hormone-receptor positive, HER2negative advanced breast cancer. In our study, we used three different AIs, letrozole, anastrozole, and exemestane, which are the most commonly used AIs for breast cancer. At times in the treatment, we were obliged to shift patients 
from one drug to another. As there are no specific criteria available to choose any one drug over another, except for drug availability, and there are no specific recommendations for use of one drug in particular [29], we did not think that would significantly affect the results of the treatment, though this may be considered a limitation in our study.

The median TTP in this study was 15 months with an ORR of $31.8 \%$ and a median OS of 37 months with acceptable treatment-related side effects. These results were significantly better than those shown in the studies that investigated the efficacy of AIs alone compared with tamoxifen as a standard first-line therapy. In comparison, the median TTP was 9.4, 10.7 and 11.8 with letrozole, anastrozole and exemestane, respectively with an ORR $29 \%[14,16,20]$. The median TTP and ORR were up to 13 months and $29 \%$, respectively with first-line standard of care compared with 15 months and 31.8 in our study. In a previous chemo-endocrine study, Shankar et al. evaluated the efficacy of combination of AIs and capecitabine for 31 patients with MBC, 20 of them received it as first-line treatment with a median PFS of 21 months and OS of $63.5 \%$, coming to a final conclusion that combined capecitabin with AIs was safe and further studies were recommended to evaluate its efficacy [26]. In a second, retrospective study, Shi et al. analyzed 407 patients with advanced breast cancer, where 102 patients received combined AIs with capecitabine. They found that the median PFS was significantly longer in the combination group than that in the AIs alone group (22.0 months vs 14.0 months) and the OS was longer for the combination group than for the AIs group (66.0 months vs 49.0 months). They concluded that a significant improvement can be seen in both PFS and OS for patients treated with combination of metronomic capecitabine and AIs and they also recommended further evaluation of chemo-endocrine therapy for patients with MBC [23]. There is another chemoendocrine study conducted by Schwartzberg $e t a l$. investigated the safety and efficacy of combined fulvestrant and capecitabine in hormone-receptor positive, HER2-negative MBC, where their results demonstrated a TTP of 26.94 months, a median PFS of 14.98 months and a median OS of 28.65 months. The treatment in their protocol was well tolerated with acceptable treatment-related adverse effects and they concluded that metronomic capecitabine with fulvestrant demonstrated substantial activities in patients with hormone receptor-positive advanced breast cancer, they also recommended further exploration of combined chemo-endocrine approaches, taking into consideration the low toxicities with meaningful TTP [13]. A recent study was conducted by Li et al. on 44 patients with hormone receptor-positive MBC to evaluate the safety and efficacy of combined metronomic capecitabine with AIs in second-line setting, their results showed a TTP of 14.4 months - similar to that of our own study - an ORR of $70.5 \%$ and a PFS of 16.2 months. However, the study only investigated postmenopausal cases for efficacy of chemo-endocrine protocol after failure on the first-line AIs alone whereas in our study, chemo-endocrine therapy was investigated as a front-line treatment.

In the current study, correlation of patients and tumor characteristics with the treatment outcome was analyzed to evaluate the effects of these variables on ORR, TTP and OS. Unfortunately, this study failed to find a significant impact of patients and tumor basic characteristics on the treatment outcome; however, past studies have presented factors such as low estrogen expression, prior therapy and visceral metastasis as things that may contribute to prolongation of TTP [24]. We also tried to find the effect of hormonal status on both TTP, and OS by substratifying the patients into 3 groups; group 1 (ER+, PR+), group 2 (ER-, PR+) and group 3 (ER+, PR-). The results showed that only patients in group 3 that had high ER expression had prolonged both median TTP and OS than groups 1 and 2 which were differed from that observed in Shi $e$ t al. study where cases with lower ER expression had improvement in both TTP and OS by univariant analysis. In general, the treatment was tolerated and the reported side effects were nearly the same as that reported in other studies. Although this study showed encouraging results for the chemo-endocrine combination of metronomic capecitabine and AIs for patients with advanced breast cancer, and the treatment outcome was similar to that obtained in previous studies, there are some limitations in this research. First, this research was single-arm Phase II study without a comparative control arm. Second, there may have been selective bias regarding different basic characteristics of the patients as this study involved both pre and postmenopausal women and different follow-up duration and usage of different types of AIs. Nevertheless, the results of the current study showed significant improvement in both TTP and OS but further research is needed for a proper judgment to be determined.

\section{Conclusion}

Chemo-endocrine therapy is an emerging and encouraging method in the treatment of patients with hormonereceptor positive, HER2-negative MBC. The current study demonstrated that a combination of AIs with metronomic capecitabine was safe and effective as a frontline therapy for such patients. 


\section{Future perspective}

Frontline chemo-endocrine combination therapy for patients with advanced hormone-receptor positive, HER2negative breast cancer needs further large randomized controlled studies, possibly including different AIs separately in individualized studies to compare the results between them and the current standard of care.

\section{Summary points}

- Chemo-endocrine combination is an emerging and encouraging method in the treatment of metastatic breast cancer.

- Combination of metronomic capecitabine and aromatase inhibitors showed promising results in patients with metastatic breast cancer.

- The median time to progression (TTP) is up to 13 months with first-line endocrine therapy alone in metastatic hormone-receptor positive, HER2-negative breast cancer.

- The median TTP in our study is 15 months.

- Single organ metastasis had longer both TTP and overall survival than multiple organs metastasis ( $p$-value: 0.021).

- The treatment was tolerated and there is a dose reduction of capecitabine due to grade 3 hand-foot syndrome in five patients $(19.5 \%)$ only.

\section{Acknowledgments}

All senior and junior staff members and nurses in the Department of Clinical Oncology and Nuclear Medicine, Faculty of Medicine, Zagazig University is acknowledged for their help and support to complete this research.

\section{Financial \& competing interests disclosures}

The authors have no relevant affiliations or financial involvement with any organization or entity with a financial interest or financial conflict with the subject matter or materials discussed in the manuscript. This includes employment, consultancies, honoraria, stock ownership or options, expert testimony, grants or patents received or pending, or royalties.

No writing assistance was utilized in the production of this manuscript.

Informed consent disclosure

The authors state that they have obtained verbal and written informed consent from the patient/patients for the inclusion of their medical and treatment history within this case report.

\section{Open access}

This work is licensed under the Attribution-NonCommercial-NoDerivatives 4.0 Unported License. To view a copy of this license, visit http://creativecommons.org/licenses/by-nc-nd/4.0/

\section{References}

Papers of special note have been highlighted as: • of interest; $\bullet \bullet$ of considerable interest

1 Bray F, Ferlay J, Soerjomataram I, Siegel RL, Torre LA, Jemal A. Global cancer statistics 2018: GLOBOCAN estimates of incidence and mortality worldwide for 36 cancers in 185 countries. CA Cancer J. Clin. 68(6), 394-424 (2018).

2 Barni S, Cabiddu M, Petrelli F. Chemo-hormonal therapy for metastatic breast cancer patients: treatment strategy. EJC Suppl. 6 (14), 13-20 (2008).

3 Corona SP, Sobhani N, Ianza A et al. Advances in systemic therapy for metastatic breast cancer: future perspectives. Med. Oncol. 34(7), 119 (2017).

4 Dunnwald LK, Rossing M, Li CI. Hormone receptor status, tumor characteristics, and prognosis: a prospective cohort of breast cancer patients. Breast Cancer Res. 9(1), R6 (2007).

5 Buzdar AU. Phase III study of letrozole versus tamoxifen as first-line therapy of advanced breast cancer in postmenopausal women: analysis of survival and update of efficacy from the international letrozole breast cancer group. J. Clin. Oncol. 22(15), 3199-3200 (2004).

6 Kataoka M, Yamaguchi Y, Moriya Y et al. Antitumor activity of chemoendocrine therapy in premenopausal and postmenopausal models with human breast cancer xenografts. Oncol. Rep. 27(2), 303-310 (2012).

7 Kerbel RS, Kamen BA. The anti-angiogenic basis of metronomic chemotherapy. Nat. Rev. Cancer 4(6), $423-436$ (2004).

- Evaluates the antiangiogenic basis of metronomic chemotherapy.

8 Sui M, Jiang D, Hinsch C, Fan W. Fulvestrant (ICI 182, 780) sensitizes breast cancer cells expressing estrogen receptor alpha to vinblastine and vinorelbine. Breast Cancer Res. Treat. 121(2), 335-345 (2010). 
9 Ikeda H, Taira N, Nogami T et al. Combination treatment with fulvestrant and various cytotoxic agents (doxorubicin, paclitaxel, docetaxel, vinorelbine, and 5-fluorouracil) has a synergistic effect in estrogen receptor-positive breast cancer. Cancer Sci. 102(11), 2038-2042 (2011).

10 Kataoka M, Yamaguchi Y, Moriya Y et al. Antitumor activity of chemoendocrine therapy in premenopausal and postmenopausal models with human breast cancer xenografts. Oncol. Rep. 27(2), 303-310 (2012).

11 de la Haba-Rodriguez J, Mancha RG, Manga GP et al. Exemestane and chemotherapy as first-line treatment of metastatic breast cancer: results of a Phase II study. Clin. Breast Cancer 10(4), 313-317 (2010).

12 Aurilio G, Munzone E, Botteri E et al. Oral metronomic cyclophosphamide and methotrexate plus fulvestrant in advanced breast cancer patients: a mono-institutional case-cohort report. Breast J. 18(5), 470-474 (2012).

13 Schwartzberg LS, Wang G, Somer BG et al. Phase II trial of fulvestrant with metronomic capecitabine for postmenopausal women with hormone receptor-positive, HER2-negative metastatic breast cancer. Clin. Breast Cancer 14(1),13-19 (2014).

14 Mouridsen H, Gershanovich M, Sun Y et al. Phase III study of letrozole versus tamoxifen as first-line therapy of advanced breast cancer in postmenopausal women: analysis of survival and update of efficacy from the International Letrozole Breast Cancer Group. J. Clin. Oncol. 21(11), 2101-2109 (2003).

15 Therasse P, Arbuck SG, Eisenhauer EA et al. New guidelines to evaluate the response to treatment in solid tumors. European Organization for Research and Treatment of Cancer, National Cancer Institute of the United States, National Cancer Institute of Canada. J. Natl Cancer Inst. 92(3), 205-216 (2000).

-. Evaluates the new guidelines in treatment of solid tumors.

16 Paridaens RJ, Dirix LY, Beex LV et al. Phase III study comparing exemestane with tamoxifen as first-line hormonal treatment of metastatic breast cancer in postmenopausal women: the European Organisation for Research and Treatment of Cancer Breast Cancer Cooperative Group. J. Clin. Oncol. 26(30), 4883-4890 (2008).

17 Ellis MJ, Llombart-Cussac A, Feltl D et al. Fulvestrant $500 \mathrm{mg}$ versus anastrozole $1 \mathrm{mg}$ for the first-line treatment of advanced breast cancer: overall survival analysis from the Phase II FIRST study. J. Clin. Oncol. 33(32), 3781-3787 (2015).

18 Robertson JFR, Bondarenko IM, Trishkina E et al. Fulvestrant $500 \mathrm{mg}$ versus anastrozole $1 \mathrm{mg}$ for hormone receptor-positive advanced breast cancer (FALCON): an international, randomised, double-blind, phase 3 trial. Lancet 388(10063), 2997-3005 (2016).

19 Ali S, Coombes RC. Endocrine-responsive breast cancer and strategies for combating resistance. Nat. Rev. Cancer 2(2). 101-112 (2002).

20 Nabholtz JM, Buzdar A, Pollak M et al. Anastrozole is superior to tamoxifen as first-line therapy for advanced breast cancer in postmenopausal women: results of a North American multicenter randomized trial. Arimidex Study Group. J. Clin. Oncol. 18(22), 3758-3767 (2000).

21 Bonneterre J, Buzdar A, Nabholtz JM et al. Anastrozole is superior to tamoxifen as first-line therapy in hormone receptor positive advanced breast carcinoma. Cancer 92(9), 2247-2258 (2001).

22 Mouridsen HT. Aromatase inhibitors in advanced breast cancer. Semin. Oncol. 31(6_Suppl. 12), 3-8 (2004).

23 Shi W, Wang X, Bi X et al. Combination of aromatase inhibitors with metronomic capecitabine: a new chemoendocrine treatment for advanced breast cancer. J. Cancer Ther. 10(2), 146-156 (2019).

24 Bottini A, Generali D, Brizzi MP et al. Randomized Phase II trial of letrozole and letrozole plus low-dose metronomic oral cyclophosphamide as primary systemic treatment in elderly breast cancer patients. J. Clin. Oncol. 24(22), 3623-3628 (2006).

25 Nukatsuka M, Saito H, Nakagawa F et al. Oral fluoropyrimidine may augment the efficacy of aromatase inhibitor via the downregulation of estrogen receptor in estrogen-responsive breast cancer xenografts. Breast Cancer Res. Treat. 128(2), 381-390 (2011).

26 Shankar A, Roy S, Rath GK et al. Aromatase inhibition and capecitabine combination as 1 st or 2 nd line treatment for metastatic breast cancer - a retrospective analysis. Asian Pac. J. Cancer Prev. 16(15), 6359-6364 (2015).

27 Li JW, Zuo WJ, Ivanova D, Jia XQ, Lei L, Liu GY. Metronomic capecitabine combined with aromatase inhibitors for new chemoendocrine treatment of advanced breast cancer: a Phase II clinical trial. Breast Cancer Res. Treat. 173(2), 407-415 (2019).

28 Ghannam A, Khedr RA. Preliminary results of capecitabine metronomic chemotherapy combined with exemestane in advanced breast cancer - a single-arm Phase II study. Cancer Biol. 9(1), 43-50 (2019).

29 Cardoso F, Senkus E, Costa A et al. 34th ESO-ESMO International Consensus Guidelines for Advanced Breast Cancer (ABC 4). Ann. Oncol. 29(8), 1634-1657 (2018). 